\title{
ANALISIS KEBUTUHAN AIR BERSIH IPA PDAM SAMBOJA KUTAI KARTANEGARA
}

\author{
Irna Hendriyani ${ }^{1)}$, Martheana Kencanawati ${ }^{2)}$, Agus Nur Salam ${ }^{3)}$ \\ Program Studi Teknik Sipil, Fakultas Teknik Sipil dan Perencanaan, Universitas Balikpapan \\ Email: ${ }^{1}$ irna.hendriyani@uniba-bpn.ac.id
}

\begin{abstract}
ABSTRAK
Masalah penyediaan air bersih saat ini menjadi perhatian khusus negara-negara maju maupun negara yang sedang berkembang. Indonesia sebagai salah satu negara berkembang, tidak lepas dari permasalahan penyediaan air bersih bagi masyarakatnya. Salah satu masalah pokok yang dihadapi adalah kurang tersedianya sumber air bersih, belum meratanya pelayanan penyediaan air bersih terutama di pedesaan dan sumber air bersih yang ada belum dimanfaatkan secara maksimal. Penelitian ini bertujuan untuk menganalisis kebutuhan air bersih dari IPA PDAM Samboja yang menggunakan 2 pompa pada 10 tahun yang akan datang (2028). Dengan menggunakan data primer dan sekunder yang diperoleh dari PDAM Samboja dan beberapa referensi yang berhubungan, didapatkan bahwa kebutuhan air bersih IPA PDAM Tirta Mahakam Samboja dengan 2 pompa, pada tahun 2018 sebesar 2.599,5 $\mathrm{m}^{3} /$ hari. Dengan perkiraan hasil jumlah pelanggan pada 10 tahun yang akan datang (2028) diperoleh jumlah kebutuhan air sebesar $3.048 \mathrm{~m}^{3} / \mathrm{hari}$. Karenanya diperlukan penambahan 1 pompa pada IPA PDAM Samboja agar tetap dapat melayani kebutuhan pelanggan pada 10 tahun mendatang
\end{abstract}

Kata kunci: IPA PDAM, kebutuhan air bersih, penyediaan air bersih 


\section{PENDAHULUAN}

Masalah penyediaan air bersih saat ini menjadi perhatian khusus negara-negara maju maupun negara yang sedang berkembang. Indonesia sebagai salah satu negara berkembang, tidak lepas dari permasalahan penyediaan air bersih bagi masyarakatnya. Salah satu masalah pokok yang dihadapi adalah kurang tersedianya sumber air bersih, belum meratanya pelayanan penyediaan air bersih terutama di pedesaan dan sumber air bersih yang ada belum dimanfaatkan secara maksimal. Di kota-kota besar sumber air bersih yang dimanfaatkan oleh PDAM telah tercemari oleh limbah industri dan limbah domestik, sehingga beban pengelolaan air bersih semakin meningkat.

Dalam rangka memenuhi kebutuhan air bersih yang semakin meningkat, dimana debit sumber air yang mengalami naik turunnya debit sungai tiap musimnya maka PDAM Samboja perlu mengkaji kembali kebutuhan air bersih untuk wilayah kecamatan Samboja. Terutama untuk wilayah pelayanan IPA PDAM Tirta Mahakam Samboja pada saat sekarang dan masa yang akan datang, agar kebutuhan masyarakat wilayah pelayanan IPA Tirta Mahakam akan air bersih dapat terpenuhi.

PDAM Tirta Mahakam Samboja merupakan cabang PDAM Tirta Mahakam yang ada di Tenggarong dan merupakan IPA yang cukup besar kapasitasnya dengan debit sungai \pm 200 liter/detik. Tidak menutup kemungkinan masalah yang ditimbulkan IPA Tirta Mahakam Samboja dapat berpengaruh besar pada masyarakat/pelanggan di Kecamatan Samboja dengan jumlah pengiriman air baku sekitar $2.682 \mathrm{~m}^{3}$ yang menghasilkan air bersih sekitar 2.559,5 $\mathrm{m}^{3}$ di setiap harinya dari sungai merdeka, yang memiliki 2 pompa yaitu sekitar 50 liter/detik dan 40 liter/detik yang menghasilkan air bersih sekitar 30 liter/detik ditiap pompanya.

Permasalahan dalam penelitian ini adalah berapakah besar kapasitas air bersih yang disalurkan dan apakah ketersediaan air IPA PDAM Samboja dengan 2 pompa dapat memenuhi kebutuhan air bersih hingga 10 tahun ke depan?

Maka tujuan peneliltian ini adalah menganalisis kebutuhan air bersih pada IPA PDAM Samboja dengan 2 pompa untuk 10 tahun kedepan.

Batasan masalah dalam penelitian adalah kebutuhan air 10 tahun ke depan yang diperhitungkan berdasarkan pertumbuhan penduduk wilayah
Kecamatan Samboja berdasarkan metode geometrik, tidak membahas kualitas air dan perhitungan bangunan air, tidak menjelaskan masalah perpipaan, tidak menghitung tekanan air, tidak menjelaskan biaya pengolahan serta tarif pemakaian air.

\section{TINJAUAN PUSTAKA}

\section{Air Bersih}

Sesuai Peraturan Menteri Kesehatan RI No 416/Menkes/PER/IX/1990 yang dimaksud dengan air bersih adalah air yang jernih, tidak berwarna, tidak berbau, tidak berasa, dan tidak mengandung mineral/kuman-kuman yang membahayakan tubuh. Berdasarkan Keputusan Menteri Kesehatan Republik Indonesia Nomor 1405/Menkes/SK/XI/2002 tentang Persyaratan Kesehatan Lingkungan Kerja Perkantoran dan Industri terdapat pengertian mengenai air bersih yaitu air yang dipergunakan untuk keperluan sehari-hari dan kualitasnya memenuhi persyaratan kesehatan air bersih sesuai dengan peraturan perundang-undangan yang berlaku dan dapat diminum apabila dimasak.

Air bersih merupakan air yang tidak menyebabkan penyakit bagi manusia. Oleh karena itu, air tersebut hendaknya diusahakan memenuhi persyaratan-persyaratan kesehatan, sekurangkurangnya diusahakan mendekati persyaratan air yang telah ditentukan (Kusnoputranto, 2000).

\section{Siklus Hidrologi}

Siklus air atau siklus hidrologi adalah sirkulasi air yang tidak pernah berhenti dari atmosfer ke bumi dan kembali ke atmosfer melalui kondensasi, presipitasi, evaporasi dan transpirasi. Pemanasan air laut oleh sinar matahari merupakan kunci proses siklus hidrologi tersebut dapat berjalan secara terus menerus. Air berevaporasi, kemudian jatuh sebagai presipitasi dalam bentuk hujan, hujan es, hujan salju, hujan gerimis atau kabut.

Pada perjalanan menuju bumi beberapa presipitasi dapat berevaporasi kembali ke atas atau langsung jatuh yang kemudian diintersepsi oleh tanaman sebelum mencapai tanah. Setelah mencapai tanah, siklus hidrologi terus bergerak secara kontinu dalam tiga cara yang berbeda, yaitu:

1. Evaporasi atau transpirasi adalah air yang ada di laut, di daratan, di sungai, di tanaman, dan sebagainya. kemudian akan menguap ke angkasa 
Analisis Kebutuhan Air Bersih..., Irna Hendriyani ${ }^{(1)}$, Martheana Kencanawati ${ }^{(2)}$, Agus Nur Salam ${ }^{(3)}$

(atmosfer) dan kemudian akan menjadi awan. Pada keadaan jenuh uap air (awan) itu akan menjadi bintik-bintik air yang selanjutnya akan turun (precipitation) dalam bentuk hujan, salju, hujan es.

2. Infiltrasi atau Perkolasi ke dalam tanah adalah air bergerak ke dalam tanah melalui celah-celah dan pori-pori tanah dan batuan menuju muka air tanah. Air dapat bergerak akibat aksi kapiler atau air dapat bergerak secara vertikal atau horizontal di bawah permukaan tanah hingga air tersebut memasuki kembali sistem air permukaan.

3. Air Permukaan adalah air bergerak di atas permukaan tanah dekat dengan aliran utama dan danau, makin landai lahan dan makin sedikit pori-pori tanah, maka aliran permukaan semakin besar. Aliran permukaan tanah dapat dilihat biasanya pada daerah urban. Sungai-sungai bergabung satu sama lain dan membentuk sungai utama yang membawa seluruh air permukaan disekitar daerah aliran sungai menuju laut.

Dari siklus hidologi inilah kebutuhan kita akan air bersih secara terus menerus dapat dipenuhi dikarenakan air merupakan sumber daya alam yang dapat diperbarui (renewable). Akan tetapi karena jumlah air yang relatif tetap sementara pertumbuhan akan air bersih semakin meningkat maka diperlukan pendistribusian yang teratur sehingga tidak terjadi kekurangan air.

\section{Sistem Pengelolaan Air Bersih}

Air baku adalah air yang digunakan sebagai sumber bahan baku dalam penyediaan air bersih. Sumber air baku yang dapat digunakan untuk penyediaan air bersih yaitu air hujan, air permukaan, (air sungai, air danau, air rawa) air tanah (air tanah dangkal, air tanah dalam, mata air). Untuk itu perlu adanya sistem pengolahan air bersih yang digunakan PDAM dalam memenuhi standar kualitas air bersih/minum antara lain unit Instalasi Pengolahan Air (IPA) yang diperlukan dalam pengolahan air. IPA Tirta Mahakam Samboja memiliki dua alat dan sistem pengolahan air yang berbeda karena ada penambahan alat pengolahan yang baru, namun pengolahan yang lama masih digunakan karena untuk mencukupi kebutuhan air pada pelanggan.

Berikut adalah sistem pengolahan air IPA Tirta Mahakam Samboja:
1. Sungai Merdeka

Sumber air baku PDAM Samboja adalah air permukaan sungai merdeka. Kondisi sekarang sungai merdeka mempunyai kedalaman sekitar 25 m. 100\% air bersumber dari sungai merdeka. Sungai merdeka adalah sungai yang ditumbuhi banyak akar, sehingga disaat pergantian musim kualitas air tidak baik dan lebih banyak menggunakan bahan kimia pada saat pengolahannya, akan tetapi ini tidak berlangsung lama karena bila musim sudah normal kualitas air kembali normal. Pipa PDAM 70\% lokasinya di bawah pondasi jalan, yang menyebabkan kesulitan dalam perbaikan jika terjadinya kerusakan atau gangguan pada pipa.

2. Rumah pompa intake

Rumah pompa intake merupakan bangunan yang berfungsi untuk menutupi pompa dari hujan atau panas matahari, dimana pompa menyedot air yang sudah disaring untuk didistribusikan ke pengolahan. Pada IPA Samboja memiliki dua rumah pompa yang berada didua tempat yakni bersebelahan sekitar $100 \mathrm{~m}$, dari jarak keduanya, yang masing-masing memiliki kapasitas yang berbeda. Yakni rumah pompa 1 terdapat 2 pompa yaitu $22 \mathrm{kw}$ dan $45 \mathrm{kw}$ yang menghasilkan sekitar 50 liter/detik, dan rumah pompa 2 terdapat 3 pompa yaitu $37 \mathrm{kw}$ yang menghasilkan sekitar 40 liter/detik. Dalam pengoperasianya pompa dihidupkan secara bergantian.

\section{Bahan Kimia}

Proses pengolahan ini menggunakan beberapa bahan kimia yaitu:

a. Kaporit. Berfungsi untuk membunuh bakteri, virus dan kuman, serta untuk menjernihkan air.

b. Tawas atau aluminium sulfat. Berfungsi untuk mengikat partikel-partikel halus yang melayang agar membentuk flok. Bahan ini diinjeksikan pada pipa air masuk keproses penjernihan.

c. Kapur atau Soda Ash. Berfungsi untuk menetralisasi $\mathrm{pH}$ air dibubuhkan dengan electromotor sebelum masuk ke reservoir.

Pada proses ini air baku langsung diberi bahan kimia pada saat air baku disalurkan ke pengolahan selanjutnya proses melalui injeksi. Disini terdapat dua pengolahan yaitu proses pengolahan bahan kimia 1 dan proses pengolahan bahan kimia 2 . 
4. Proses pengolahan air yang didistribusikan setelah diberi bahan kimia.

a. Aerator, adalah suatu proses penambahan udara/oksigen dalam air dengan membawa air dan udara ke dalam kontak yang dekat, dengan cara menyemprotkan air ke udara (air ke dalam udara) atau dengan memberikan gelembung-gelembung halus udara dan membiarkannya naik melalui air (udara ke dalam air). Sumber lain menjelaskan bahwa aerasi adalah suatu proses atau usaha dalam menambahkan konsentrasi oksigen yang terkandung dalam air limbah, agar proses oksidasi biologi oleh mikroba akan dapat berjalan dengan baik. Dalam melakukan proses aerasi ini perlu menggunakan alat yang dinamakan aerator. Prinsip kerja alat ini adalah untuk menambahkan oksigen terlarut di dalam air tersebut. Kemudian yang menjadi tugas utama dari aerator ini adalah memperbesar permukaan kontak antara air dan udara.

b. WTP (Water Treatment Plant). Ini adalah bangunan pokok dari sistem pengolahan air bersih. Bangunan ini beberapa bagian, yakni koagulasi, flokulasi, sedimentasi, filtrasi dan desinfeksi.

1) Koagulasi. Disinilah proses kimiawi terjadi, pada proses koagulasi ini dilakukan proses destabilisasi partikel koloid, karena pada dasarnya air sungai atau air kotor biasanya berbentuk koloid dengan berbagai partikel koloid yang terkandung didalamnya. Tujuan proses ini adalah untuk memisahkan air dengan pengotor yang terlarut didalamnya, analoginya seperti memisahkan air pada susu kedelai. Pada unit ini terjadi rapid mixing (pengadukan cepat) agar koagulan dapat terlarut merata dalam waktu singkat. Bentuk alat pengaduknya dapat bervariasi, selain rapid mixing, dapat menggunakan hidrolis (hydrolic jump atau terjunan) atau mekanis (menggunakan batang pengaduk).

2) Flokulasi. Selanjutnya air masuk ke unit flokulasi. Tujuannya adalah untuk membentuk dan memperbesar flok (pengotor yang terendapkan). Di sini dibutuhkan lokasi yang alirannya tenang namun tetap ada pengadukan lambat (slow mixing) supaya flok menumpuk.
Untuk meningkatkan efisiensi, biasanya ditambah dengan senyawa kimia yang mampu mengikat flok-flok tersebut.

3) Sedimentasi. Bangunan ini digunakan untuk mengendapkan partikel-partikel koloid yang sudah didestabilisasi oleh unit sebelumnya. Unit ini menggunakan prinsip berat jenis. Berat jenis partikel kolid (biasanya berupa lumpur) akan lebih besar daripada berat jenis air. Pada masa kini, unit koagulasi, flokulasi dan sedimentasi telah ada yang dibuat tergabung yang disebut unit aselator.

4) Filtrasi. Sesuai dengan namanya, filtrasi adalah untuk menyaring dengan media butiran. Media butiran ini biasanya terdiri dari antrasit, pasir silica dan kerikil silica dengan ketebalan berbeda. Cara ini dilakukan dengan metode gravitasi.

5) Desinfeksi. Setelah bersih dari pengotor, masih ada kemungkinan ada kuman dan bakteri yang hidup, sehingga ditambahkanlah senyawa kimia yang dapat mematikan kuman ini, biasanya berupa penambahan chlor, ozonisasi, UV, pemabasan, dan lain-lain sebelum masuk ke bangunan selanjutnya, yakni reservoir.

6) Reservoir. Berfungsi sebagai tempat penampungan sementara air bersih sebelum didistribusikan melalui pipapipa secara gravitasi atau pompa.

Gabungan dari unit-unit pengolahan air ini disebut Instalasi Pengolahan Air (IPA). Untuk menghemat biaya pembangunan, unit intake, WTP dan reservoir dapat dibangun dalam satu kawasan dengan ketinggian yang cukup tinggi, sehingga tidak diperlukan pumping station dengan kapasitas pompa dorong yang besar untuk menyalurkan air dari WTP ke reservoir. Pada akhirnya, dari reservoir, air bersih siap untuk didistribusikan melalui pipa-pipa dengan berbagai ukuran ke tiap daerah distribusi.

Berikut proses pengolahan air bersih dengan sumber air baku yang berasal dari air permukaan dapat digambarkan seperti pada Gambar 1. 


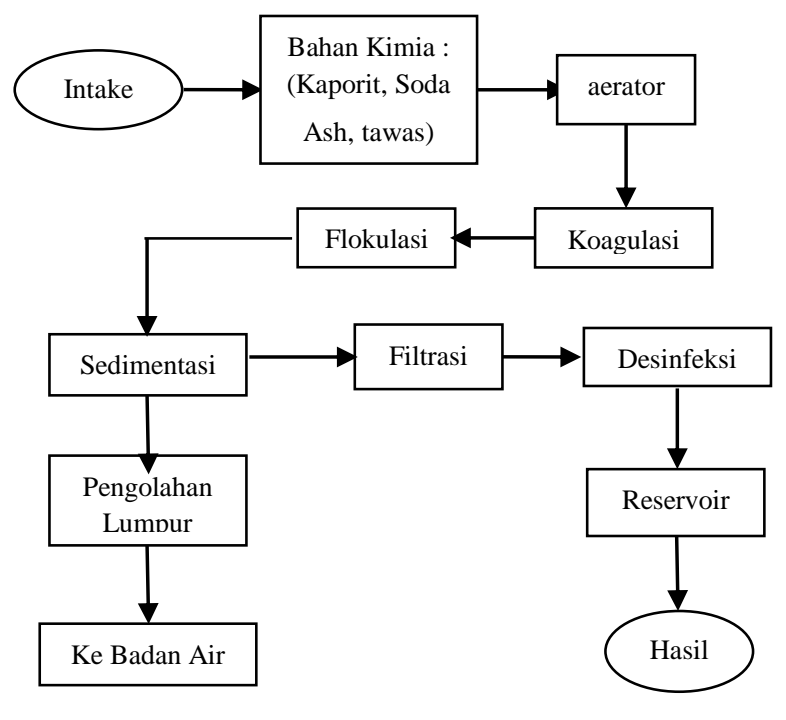

Gambar 1. Skema Pengolahan Air Sumber: PDAM (2018)

\section{Kebutuhan Air Bersih}

Air merupakan kebutuhan dasar bagi manusia, yang harus tersedia dalam kuantitas yang cukup dan kualitas yang memenuhi syarat (tidak berbau, tidak berasa, tidak berwarna, dan tidak mengandung zat radioaktif). Air bersih merupakan satu dari kebutuhan primer yang harus dipenuhi agar kelangsungan hidup manusia dapat berlanjut. Kualitas, kuantitas dan kontinuitas dari air yang dikonsumsi manusia akan berperan besar pada kehidupan masyarakat. Oleh sebab itu perlu dilakukan analisa perhitungan kebutuhan air bersih.

Kebutuhan air bersih suatu daerah pelayanan terdiri dari kebutuhan domestik dan kebutuhan nondomestik. Untuk lebih rincinya akan dijelaskan satu per satu:

1. Kebutuhan domestik

Yaitu kebutuhan air bersih untuk pemenuhan kebutuhan sehari-hari atau rumah tangga seperti: untuk air minum, memasak, kesehatan individual (mandi), mencuci dan sebagainya.

2. Kebutuhan non-domestik

Yaitu kebutuhan air bersih yang digunakan untuk beberapa kegiatan seperti:

- Kebutuhan fasilitas umum air bersih: yaitu kebutuhan air bersih untuk kegiatan tempattempat ibadah, terminal dan rekreasi.

- Kebutuhan institusional: kebutuhan air bersih untuk kegiatan perkantoran, sekolah dan instansi pemerintahan.
- Kebutuhan komersial dan industri: yaitu kebutuhan air bersih pada hotel, pasar, pertokoan restoran. Sedangkan kebutuhan air bersih untuk industri biasanya digunakan untuk air pendingin, air pada boiler untuk memanas.

\section{Metode Pertumbuhan Penduduk}

Pertumbuhan penduduk merupakan salah satu faktor yang penting dalam masalah kebutuhan air bersih dan masalah penduduk pada khususnya. Karena disamping berpengaruh terhadap jumlah dan komposisi penduduk juga akan berpengaruh terhadap kondisi ketersediaan air baku. Pertumbuhan penduduk adalah perubahan jumlah penduduk baik pertambahan maupun penurunnya. Angka pertumbuhan penduduk adalah tingkat pertambahan penduduk suatu wilayah atau negara dalam suatu jangka waktu tertentu, dinyatakan dalam persentase.

Langkah pertama dalam perencanaan suatu sistem penyediaan air adalah memperhitungkan kebutuhan air. Data masa lalu tentang kota yang sedang telah atau data dari kota-kota lain yang serupa merupakan petunjuk terbaik dalam pemilihan suatu angka tentang penggunaan air bagi tujuan-tujuan perencanaan.

Metode yang digunakan dalam memproyeksi jumlah penduduk dimana hasilnya merupakan harga pendekatan dari hasil sebenarnya adalah sebagai berikut:

\section{Metode aritmatika}

Cara ini didasarkan pada kenaikan rata-rata jumlah penduduk dengan menggunakan data terakhir dan rata-rata sebelumnya.

$$
\begin{aligned}
& \mathrm{Pn}=\mathrm{Pt}+\mathrm{I}(\mathrm{n}) \\
& \mathrm{I}=(\mathrm{Po}-\mathrm{Pt}) \mathrm{t}
\end{aligned}
$$

Dimana:

$$
\begin{aligned}
\mathrm{Pn}= & \text { Jumlah penduduk pada tahun ke } \mathrm{n} ; \\
\mathrm{Po}= & \text { Jumlah penduduk yang diketahui pada } \\
& \text { tahun ke } 1 ; \\
\mathrm{Pt}= & \text { Jumlah penduduk pada tahun terakhir } \\
\mathrm{t}= & \text { Jumlah tahun yang diketahui } \\
\mathrm{I}= & \text { Rata-rata pertumbuhan penduduk tiap } \\
& \text { tahun; }
\end{aligned}
$$

Metode ini sangat sesuai digunakan untuk daerah yang mempunyai angka pertumbuhan penduduk yang rendah atau pada daerah-daerah 
Analisis Kebutuhan Air Bersih..., Irna Hendriyani ${ }^{(1)}$, Martheana Kencanawati ${ }^{(2)}$, Agus Nur Salam ${ }^{(3)}$

dengan derajat pertumbuhan penduduk tetap apabila jumlah dan kepadatan penduduk menjadi maksimum.

\section{Metode Geometri}

Metode ini merupakan perhitungan perkembangan populasi berdasarkan pada angka kenaikan penduduk rata-rata pertahun.

$$
\operatorname{Pn}=\operatorname{Po}(1+r)^{n}
$$

Dimana:

$\mathrm{Pn}=$ Jumlah penduduk pada tahun ke $\mathrm{n}$

Po $=$ Jumlah penduduk pada tahun dasar;

$\mathrm{r}=$ Laju pertumbuhan penduduk

$\mathrm{n}=$ Jumlah interval

Metode ini akan menghasilkan nilai yang lebih tinggi, karena presentase pertambahan sesungguhnya tidak pernah tetap, tetapi presentase tersebut akan menurun bilamana suatu daerah mencapai batas optimum. Sehingga metode ini sangat sesuai untuk daerah yang mempunyai pertambahan penduduk yang tetap.

\section{Perhitungan Kebutuhan Air}

Setelah pertumbuhan penduduk diproyeksikan maka langkah selanjutnya adalah perhitungan kebutuhan air dengan persamaan berikut:

Qmd $\quad=$ Jumlah penduduk $\times$ q ......(5)

Qmdmax $\quad=$ Qmd $\times \mathrm{F}$ (maxday)

Qmdpeak hour $=$ Qmd $\times \mathrm{F}($ peak hour $)$

Dimana :

Qmd = Kebutuhan Air (1/hari)

$\mathrm{Q} \quad=$ Konsumsi Air per orang per hari

Qmdmax = Kebutuhan Harian Maksimum

Fpeak hour $=$ Faktor Jam Puncak

\section{METODE PENELITIAN}

\section{Jenis Penelitian}

Penelitian ini merupakan penelitian deskriptif kuantitatif untuk mengetahui kebutuhan air bersih untuk wilayah pelayanan IPA PDAM Samboja Kutai Kertanegara, serta meninjau ketersediaan air sungai merdeka yang merupakan sumber air baku IPA tersebut.

\section{Variabel Penelitian}

Variabel dalam penelitian ini adalah jumlah pelanggan aktif menggunakan air dari PDAM Samboja Kutai Kertanegara, debit yang dibutuhkan untuk memenuhi kebutuhan pelanggan dan debit yang tersedia dari Sungai Merdeka.

\section{Sumber Data}

Data yang digunakan dalam penelitian ini berupa:

a. Data Primer. Untuk mendapatkan data primer dilakukan dengan cara wawancara, observasi, dan dokumentasi di PDAM Samboja Kutai Kertanegara.

b. Data Sekunder. Data sekunder yang diperlukan adalah jumlah penduduk yang diperoleh dari laporan tahunan Kecamatan Samboja, daerah cakupan pelayanan yang diperoleh dari laporan tahunan PDAM, debit sungai merdeka yang diperoleh dari data tahunan PDAM, serta debit air total produksi dalam per-hari.

\section{Teknik Pengumpulan Data}

Adapun teknik pengumpulan data yang digunakan pada penelitian ini adalah sebagai berikut:

1. Tahap Persiapan

Dalam hal ini tim mempersiapkan data sekunder dari buku, dokumen, dan referansi yang berhubungan. Kemudian menentukan responden dalam hal ini adalah 2 orang staf PDAM Samboja.

2. Pengumpulan Data

Data yang didapat merupakan data skunder dari PDAM Samboja Kutai Kertanegara khususnya wilayah pelayanan IPA Sungai Merdeka yang terdiri dari:

1. Data jumlah pelanggan aktif.

2. Data kebutuhan air bersih tiap jenis pelanggan.

3. Data debit sumur dalam.

4. Peta daerah daerah pelayanan berdasarkan sumber air baku.

3. Analisis Data

Tahap analisis dilakukan perhitungan berdasarkan data-data yang diperoleh dengan tahap-tahap sebagai berikut:

a. Menghitung kebutuhan air bersih wilayah pelayanan IPA Sungai Merdeka PDAM 
Analisis Kebutuhan Air Bersih..., Irna Hendriyani ${ }^{(1)}$, Martheana Kencanawati ${ }^{(2)}$, Agus Nur Salam ${ }^{(3)}$

Samboja Kutai Kertanegara dilakukan dengan cara:

1). Realisasi penggunaan.

2). Estimasi penggunaan teoritis.

b. Menghitung proyeksi jumlah pelanggan aktif dan kebutuhan air bersih tahun 2020 .

c. Menghitung kebutuhan air bersih PDAM Samboja Kutai Kertanegara yang harus tersedia untuk wilayah pelayanan IPA Sungai Merdeka PDAM Samboja Kutai Kertanegara.

d. Mengitung kebutuhan air bersih untuk tiap jenis pelanggan.

e. Menghitung proyeksi debit Sungai Merdeka yang dibutuhkan dari tahun 2007 sampai dengan tahun 2020. f. Menghitung proyeksi kapasitas debit pompa Sungai Merdeka dari tahun 2007 sampai dengan tahun 2020.

\section{HASIL DAN PEMBAHASAN}

\section{Analisis Kebutuhan Domestik}

Merupakan kebutuhan yang paling penting karena ini merupakan pemenuhan kebutuhan seharihari atau rumah tangga. Analisa untuk kebutuhan domestik ini dilakukan dengan menganalisa pertumbuhan penduduk pada wilayah yang direncanakan. Kebutuhan domestik kota dibagi dalam beberapa kategori yaitu seperti pada Tabel 1 .

Tabel 1. Kriteria Perencanaan Air Bersih

\begin{tabular}{|c|c|c|c|c|c|c|}
\hline \multirow{3}{*}{ No } & \multirow{3}{*}{ Uraian } & \multicolumn{5}{|c|}{ Kategori Kota Berdasarkan Jumlah Penduduk (dalam ribuan) } \\
\hline & & $>1.000$ & $500-1.000$ & $100-500$ & $20-100$ & $<20$ \\
\hline & & $\begin{array}{c}\text { Kota } \\
\text { Metropolitan }\end{array}$ & Kota Besar & Kota Sedang & Kota Kecil & Desa \\
\hline I & II & III & IV & $\mathrm{V}$ & VI & VII \\
\hline 1. & $\begin{array}{l}\text { Konsumsi unit sambungan } \\
\text { rumah (SR) (liter/orang/hari) }\end{array}$ & 190 & 170 & 150 & 130 & 80 \\
\hline 2. & $\begin{array}{l}\text { Konsumsi unit hidran (HU) } \\
\text { (liter/orang/hari) }\end{array}$ & 30 & 30 & 30 & 30 & 30 \\
\hline 3. & \begin{tabular}{l} 
Konsumsi Unit Non \\
Domestik \\
a. Niaga kecil (liter/unit/hari) \\
b. Niaga Besar (liter/unit/hari)\} $\\
{\text { c. Industri Besar }} \\
{\text { (liter/detik/ha) }} \\
{\text { d. Pariwisata (liter/detik/ha) }}$ & $\begin{array}{c}600-900 \\
1000-5000 \\
0,2-0,8 \\
0,1-0,3\end{array}$ & $\begin{array}{c}600-900 \\
1000-5000 \\
0,2-0,8 \\
0,1-0,3\end{array}$ & & $\begin{array}{c}600 \\
1500 \\
0,2-0,8 \\
0,1-, 3\end{array}$ & \\
\hline 4. & Kehilangan air $(\%)$ & $20-30$ & $20-30$ & $20-30$ & 20 - 30 & $20-30$ \\
\hline 5. & Faktor hari Maksimum & $\begin{array}{c}1,1 \\
* \text { harian } \\
\end{array}$ & $\begin{array}{c}1,1 \\
* \text { harian } \\
\end{array}$ & $\begin{array}{c}1,1 \\
* \text { harian } \\
\end{array}$ & $\begin{array}{c}1,1 \\
\text { *harian }\end{array}$ & $\begin{array}{c}1,1 \\
* \text { harian } \\
\end{array}$ \\
\hline 6. & Faktor jamPuncak & $\begin{array}{c}1,5 \\
\text { *hari maks } \\
\end{array}$ & $\begin{array}{c}1,5 \\
\text { *hari maks } \\
\end{array}$ & $\begin{array}{c}1,5 \\
\text { *hari maks }\end{array}$ & $\begin{array}{c}1,5 \\
* \text { hari maks } \\
\end{array}$ & $\begin{array}{c}1,5 \\
\text { *hari maks } \\
\end{array}$ \\
\hline 7. & Jumlah Jiwa per SR & 5 & 5 & 5 & 5 & 5 \\
\hline 8. & Jumlah Jiwa per HU & 100 & 100 & 100 & $100-200$ & 200 \\
\hline 9. & $\begin{array}{l}\text { Sisa tekan di penyediaan } \\
\text { distribusi (meter) }\end{array}$ & 10 & 10 & 10 & 10 & 10 \\
\hline 10 & Jam Operasi (jam) & 24 & 24 & 24 & 24 & 24 \\
\hline 11 & $\begin{array}{l}\text { Volume reservoir (\% max day } \\
\text { demand) }\end{array}$ & 20 & 20 & 20 & 20 & 20 \\
\hline 12 & SR:HU & $\begin{array}{c}50: 50 \\
\text { s.d } \\
80: 20 \\
\end{array}$ & $\begin{array}{c}50: 50 \\
\text { s.d } \\
80: 20\end{array}$ & $80: 20$ & 70:30 & $70: 30$ \\
\hline 13 & Cakupan Pelayanan & 90 & 90 & 90 & 90 & 70 \\
\hline
\end{tabular}
\end{tabular}

Sumber: Kriteria Perencanaan Ditjen Cipta Karya Dinas PU,1998 
Analisis Kebutuhan Air Bersih..., Irna Hendriyani ${ }^{(1)}$, Martheana Kencanawati ${ }^{(2)}$, Agus Nur Salam ${ }^{(3)}$

Berdasarkan jumlah penduduk Samboja Kutai Kertanegara, yaitu sebesar 62.771 jiwa (dukcapil, 2018), maka tergolong dalam kota kecil (Cipta Karya, 1998)

Daerah wilayah pelayanan PDAM Tirta Mahakam Samboja seperti terlihat pada Tabel 2.

Sementara jumlah penduduk berdasarkan pelayanan PDAM dari tahun 20013 - 2017 seperti tercantum pada Tabel 3.

Tabel 2. Daerah Pelayanan PDAM Tirta Mahakam Samboja

\begin{tabular}{|c|c|}
\hline Kelurahan & Jalan \\
\hline Sungai Merdeka & 1. Sungai Merdeka \\
\hline Sungai Seluang & $\begin{array}{l}\text { 1. Pelajar } \\
\text { 2. Distrik } 1 \\
\text { 3. Gunung Malang } \\
\text { 4. Sei. Seluang }\end{array}$ \\
\hline Wonotirto & 1. Karya Wonotirto \\
\hline Kampung Lama & $\begin{array}{l}\text { 1. Kampung Padang } \\
\text { 2. Gunung Pasir }\end{array}$ \\
\hline Tanjung Harapan & 1. Tanjung Harapan \\
\hline Kuala Samboja & 1. Kuala Samboja \\
\hline Margumulyo & 1. Margumulyo \\
\hline Pemedas & 1. Pemedas \\
\hline
\end{tabular}

Sumber: PDAM Samboja (2017)

Tabel 3. Jumlah Penduduk Daerah Pelayanan PDAM Tahun 2013-2017

\begin{tabular}{lccccc}
\hline \multirow{2}{*}{ KELURAHAN } & \multicolumn{5}{c}{ TAHUN } \\
\cline { 2 - 6 } & 2013 & 2014 & 2015 & 2016 & 2017 \\
\hline Margomulyo & 1.277 & 1.283 & 1.287 & 1.272 & 1.267 \\
\hline Sei Merdeka & 5.160 & 5.164 & 5.168 & 5.168 & 5.168 \\
\hline Sei Seluang & 3.517 & 3.520 & 3.522 & 3.460 & 3.454 \\
\hline Wonotirto & 1.870 & 1.871 & 1.877 & 1.930 & 1.853 \\
\hline Tanjung Harapan & 1.961 & 1.962 & 1.969 & 1.974 & 2.027 \\
\hline Samboja Kuala & 6.021 & 6.020 & 6.028 & 6.121 & 6.115 \\
\hline Teluk Pemedas & 2.736 & 2.742 & 2.748 & 2.748 & 2.838 \\
\hline Kampung Lama & 1.956 & 1.961 & 1.968 & 1.973 & 1.958 \\
\hline TOTAL & 24.498 & 24.523 & 24.567 & 24.646 & 24.680 \\
\hline
\end{tabular}

Sumber: PDAM Samboja (2017)

Kecamatan Samboja dengan jumlah penduduk 24.680 jiwa (akhir tahun 2017) yang berlangganan air di PDAM Samboja termasuk golongan kota kecil.

\section{Analisa Kebutuhan Non-Domestik}

Yaitu kebutuhan air bersih untuk beberapa kegiatan yang berkaitan dengan fasilitas-fasilitas sosial ekonomi yang ada pada daerah yang direncanakan. Berikut kriteria dari kebutuhan non- domestik yang diatur dalam peraturan "Kriteria Perencanaan Ditjen Cipta Karya Dinas PU,1998".

Tabel 4. Kebutuhan Air Non Domestik Untuk Kota Kategori I, II, III, dan IV

\begin{tabular}{lcl}
\hline \multicolumn{1}{c}{ SEKTOR } & NILAI & \multicolumn{1}{c}{ SATUAN } \\
\hline Sekolah & 10 & Liter/murid/hari \\
\hline Rumah Sakit & 2.000 & Liter/unit/hari \\
\hline Masjid & 2.000 & Liter/unit/hari \\
\hline Kantor & 10 & Liter/pegawai/hari \\
\hline Pasar & 12.000 & Liter/hektar/hari \\
\hline Hotel & 150 & Liter/bed/hari \\
\hline Rumah Makan & 100 & $\begin{array}{l}\text { Liter/tempat } \\
\text { duduk/hari }\end{array}$ \\
\hline $\begin{array}{l}\text { Kompleks } \\
\text { Militer }\end{array}$ & 60 & Liter/orang/hari \\
\hline $\begin{array}{l}\text { Kawasan } \\
\text { Industri }\end{array}$ & $0,2-0,8$ & Liter/detik/hektar \\
\hline $\begin{array}{l}\text { Kawasan } \\
\text { Pariwisata }\end{array}$ & $0,1-0,3$ & Liter/detik/hektar \\
\hline
\end{tabular}

Sumber: Kriteria Perencanaan Ditjen Cipta Karya Dinas PU (1998)

Tabel 5. Kebutuhan Air Non Domestik Untuk Kategori V

\begin{tabular}{lrl}
\hline \multicolumn{1}{c}{ SEKTOR } & \multicolumn{1}{c}{ NILAI } & \multicolumn{1}{c}{ SATUAN } \\
\hline Sekolah & 5 & Liter/murid/hari \\
\hline Rumah Sakit & 200 & Liter/bed/hari \\
\hline Puskesmas & 1.200 & Liter/unit/hari \\
\hline Masjid & 3.000 & Liter/unit/hari \\
\hline Mushola & 2.000 & Liter/unit/hari \\
\hline Pasar & 12.000 & Liter/hektar/hari \\
\hline Komersial/Industri & 10 & Liter/hektar/hari \\
\hline Sumber: Kriteria Perengan
\end{tabular}

Sumber: Kriteria Perencanaan Ditjen Cipta Karya Dinas PU (1998)

Tabel 6. Kebutuhan Air Non Domestik Untuk Kategori Lain

\begin{tabular}{lcc}
\hline \multicolumn{1}{c}{ SEKTOR } & NILAI & SATUAN \\
\hline Lapangan Terbang & 10 & Liter/orang/detik \\
\hline Pelabuhan & 50 & Liter/orang/detik \\
\hline $\begin{array}{l}\text { Stasiun Kereta Api } \\
\text { dan Terminal Bus }\end{array}$ & 10 & Liter/orang/detik \\
\hline Kawasan Industri & 0,75 & Liter/detik/hektar \\
\hline
\end{tabular}

Sumber: Kriteria Perencanaan Ditjen Cipta Karya Dinas PU (1998)

\section{Perkiraan Kebutuhan Air Bersih}

Air merupakan kebutuhan dasar bagi manusia, yang harus tersedia dalam kuantitas yang cukup dan kualitas yang memenuhi syarat (tidak berbau, tidak berasa, tidak berwarna, dan tidak 
Analisis Kebutuhan Air Bersih..., Irna Hendriyani ${ }^{(1)}$, Martheana Kencanawati ${ }^{(2)}$, Agus Nur Salam ${ }^{(3)}$

mengandung zat radioaktif). Perkembangan dan pertambahan penduduk akan menentukan besarnya kebutuhan air bersih dimasa yang akan datang dimana hasil nantinya merupakan pendekatan dari hasil sebenarnya.

Dalam memperkirakan jumlah penduduk digunakan data-data jumlah penduduk tahun-tahun sebelumnya. Sedangkan yang akan dianalisa adalah daerah pelayanan PDAM Tirta Mahakam.

Kemudian dilakukan perhitungan proyeksi jumlah penduduk untuk tahun 2028 yaitu sebagai berikut dengan menggunakan metode aritmatika sebagai perbandingan dengan metode geometrik dalam mencari proyeksi penduduk:

\section{Metode Aritmatika}

$$
\begin{aligned}
& \text { Diketahui: } \begin{array}{ll}
\text { Po } & =62.771 \text { jiwa } \\
\mathrm{Pt} & =52.655 \text { jiwa } \\
\mathrm{t} & =5 \text { tahun } \\
\mathrm{n} & =15 \text { tahun }
\end{array} \\
& \begin{aligned}
\mathrm{I}= & \frac{P o-P t}{t}=\frac{62.771-52.655}{5}=2023,2 \\
\mathrm{Pn} & =\mathrm{Pt}+\mathrm{I}(\mathrm{n}) \\
& =52.655+2.023,2(15) \\
& =83.003 \text { jiwa }
\end{aligned}
\end{aligned}
$$

Jadi dengan metode Aritmatika keseluruhan perkiraan penduduk kecamatan Samboja tahun 2028 adalah 83.003 jiwa.

\section{Metode Geometrik}

$$
\begin{aligned}
& \text { Diketahui: } \quad \mathrm{Pt} \quad=52.655 \\
& \text { Po }=62.771 \\
& \mathrm{n} \quad=10
\end{aligned}
$$

$\mathrm{Pn}=\mathrm{Po}(1+\mathrm{r})^{\mathrm{n}}$

$\mathrm{r}=\left(\frac{P o}{P t}\right)^{1 / 5}-1=\left(\frac{62.771}{52.655}\right)^{1 / 5}-1=0,0357713$

Maka jumlah penduduk untuk tahun 2028 adalah:

$$
\begin{aligned}
\text { Pn } & =\text { Po }(1+\mathrm{r})^{\mathrm{n}} \\
& =62.771(1+0,0357713)^{10} \\
& =89.206,789 \text { jiwa }
\end{aligned}
$$

Jadi dengan metode Geometri keseluruhan perkiraan penduduk Kecamatan Samboja tahun 2028 adalah 89.206 jiwa.
PDAM Kecamatan Samboja membagi kelompok untuk pelanggan ada empat kelompok

\begin{tabular}{|c|c|c|}
\hline No & $\begin{array}{l}\text { Kelompok } \\
\text { Pelanggan } \\
\end{array}$ & $\begin{array}{l}\text { Keterangan } \\
\text { Pelanggan } \\
\end{array}$ \\
\hline \multirow[t]{8}{*}{1} & \multirow{8}{*}{$\begin{array}{l}\text { KELOMPOK } \\
\text { (I) }\end{array}$} & Sosial Khusus 1 (I.2) \\
\hline & & - Rumah Ibadah \\
\hline & & Sosial Khusus 2 (I.3) \\
\hline & & - Panti Asuhan \\
\hline & & - Yayasan Sosial \\
\hline & & - Sekolah Negeri/ Swasta \\
\hline & & $\begin{array}{ll}\text { - Puskesmas/Rumah Sakit } \\
\text { Pemerintah }\end{array}$ \\
\hline & & - Pasar Pemerintah \\
\hline \multirow[t]{15}{*}{2} & \multirow[t]{15}{*}{$\begin{array}{l}\text { KELOMPOK } \\
\text { (II) }\end{array}$} & $\begin{array}{l}\text { Rumah Tangga B (II.1) } \\
\text { - Rumah Sederhana } \\
\end{array}$ \\
\hline & & Instansi Pemerintah (II.2) \\
\hline & & - Kantor Pemerintah \\
\hline & & - Kolam Renang Milik \\
\hline & & Pemerintah \\
\hline & & - Gedung Olahraga/ Stadion \\
\hline & & Milik Pemerintah \\
\hline & & - Gedung Pertemuan/ Balai \\
\hline & & Pertemuan \\
\hline & & - Terminal \\
\hline & & - Kantor Dinas TNI/ Polri \\
\hline & & Niaga Kecil (II.3) \\
\hline & & - Kios/ warung/ warnet \\
\hline & & $\begin{array}{l}\text { - Toko dengan bangunan } \\
\text { maksimal } 20 \mathrm{~m} 2\end{array}$ \\
\hline & & - Salon/ Rumah sewa \\
\hline \multirow[t]{13}{*}{3} & \multirow[t]{13}{*}{$\begin{array}{l}\text { KELOMPOK } \\
\text { (III) }\end{array}$} & $\begin{array}{l}\text { Rumah Tangga C (III.1) } \\
\text { - Rumah Mewah }\end{array}$ \\
\hline & & Rumah Tangga D (III.2) \\
\hline & & - Rumah toko (ruko) \\
\hline & & - kantor (rukan) \\
\hline & & $\begin{array}{l}\text { - kost (jumlah kamar lebih dari } \\
\text { 4) }\end{array}$ \\
\hline & & Niaga Besar (III.3) \\
\hline & & - Hotel \\
\hline & & - Restoran \\
\hline & & - konsultan, notaris, Lembaga \\
\hline & & $\begin{array}{l}\text { Bantuan Hukum (LBH) } \\
\text { - cafe }\end{array}$ \\
\hline & & - Kantor perusahaan \\
\hline & & - Laundry \\
\hline & & - Bengkel Besar \\
\hline
\end{tabular}
dengan membedakan besar pemakaian serta biaya per $\mathrm{m}^{3}$ nya. Tabel 7 merupakan pembagian kelompok pelanggan PDAM Kecamatan Samboja.

Tabel 8 merupakan jumlah penduduk/ pelanggan di bulan Desember pada tahun 2017 di wilayah Instalasi Pengolahan Air Tirta mahakam Kecamatan Samboja:

Sebelum dilakukan perhitungan kebutuhan air untuk 10 tahun kedepan terlebih dahulu dilakukan perhitungan kebutuhan air untuk tahun 2018 seperti pada Tabel 9.

Tabel 7. Pembagian kelompok pelanggan PDAM Kecamatan Samboja: 


\begin{tabular}{cll}
\hline No & $\begin{array}{l}\text { Kelompok } \\
\text { Pelanggan }\end{array}$ & $\begin{array}{l}\text { Keterangan } \\
\text { Pelanggan }\end{array}$ \\
\hline 4 & KELOMPOK & Niaga Besar (IV.1) \\
& (IV) & - Hotel Bintang 2 \\
& & - Pusat Perbelanjaan dan toko \\
& modern \\
& & - Pegadaian/ Perbankkan \\
& & - Dealer Motor/ Mobil \\
& & - SPBU \\
\hline
\end{tabular}

Tabel 8. Jumlah pelanggan tahun 2017 di PDAM Samboja:

\begin{tabular}{lcc}
\hline JENIS PELAYANAN & $\begin{array}{c}\text { Jumlah } \\
\text { Pelanggan }\end{array}$ & $\begin{array}{c}\text { Jumlah Air } \\
\text { Yang Terjual } \\
\left(\mathbf{m}^{\mathbf{3}}\right)\end{array}$ \\
\hline KELOMPOK (I) & & \\
\hline Sosial Khusus 1 (I.2) & 27 & 799 \\
\hline Sosial Khusus 2 (1.3) & 29 & 1675 \\
\hline KELOMPOK (II) & & \\
\hline Rumah Tangga B (II.I) & 2308 & 57048 \\
\hline $\begin{array}{l}\text { Instansi Pemerintah } \\
\text { (II.2) }\end{array}$ & 17 & 723 \\
\hline Niaga Kecil (II.3) & 164 & 5154 \\
\hline KELOMPOK (III) & & 1628 \\
\hline Rumah Tangga C (III.I) & 18 & 44 \\
\hline Rumah Tangga D (III.2) & 1 & 1576 \\
\hline Niaga Besar I (III.3) & 9 & 77 \\
\hline KELOMPOK (IV) & \multicolumn{1}{c}{68.724} \\
\hline Niaga Besar II ( IV.1) & 2 & \\
\hline \multicolumn{1}{c}{ Total } & 2.575 & \\
\hline
\end{tabular}

Tabel 9. Jumlah kebutuhan air bersih tahun 2018

\begin{tabular}{lc}
\hline \multicolumn{1}{c}{ Jenis pelayanan } & $\begin{array}{c}\text { Kebutuhan air bersih } \\
\text { (liter/detik) }\end{array}$ \\
\hline KELOMPOK (I) & \\
Sosial Khusus 1 (I.2) & 0,625 \\
Sosial Khusus 2 (1.3) & 0,671 \\
\hline KELOMPOK (II) & \\
Rumah Tangga B (II.I) & 17,363 \\
Instansi Pemerintah (II.2) & 3,935 \\
Niaga Kecil (II.3) & 1,898 \\
\hline KELOMPOK (III) & \\
Rumah Tangga C (III.I) & 0,270 \\
Rumah Tangga D (III.2) & 0,015 \\
Niaga Besar I (III.3) & 0,156 \\
\hline KELOMPOK (IV) & \\
Niaga Besar II ( IV.1) & 0,046 \\
\hline TOTAL & 24,981 \\
\hline
\end{tabular}

Sumber: Hasil analisis

Maka kebutuhan air pada tahun 2018 adalah 24,981 liter/detik atau 2.158,358 $\mathrm{m}^{3} / \mathrm{hari}$ sedangkan air yang siap didistribusikan setiap harinya sekitar $2.599,5 \mathrm{~m}^{3} /$ hari, jadi saat ini kebutuhan air didaerah pelayanan IPA Samboja cukup tersedia. Setelah itu dilakukan pencarian data jumlah penduduk wilayah pelayanan untuk memproyeksikan jumlah penduduk untuk 10 tahun kedepannya.
Untuk mengetahui jumlah penduduk/ pelanggan untuk kebutuhan air ditahun 2028 maka digunakan metode geometri. Tapi tidak semua jumlah penduduk Samboja yang menjadi pelanggan PDAM maka yang dihitung hanya jumlah konsumen ditahun 2018 dikalikan dengan menggunakan koefisien dari proyeksi penduduk diatas yaitu $(1+0,0357713)^{10}$.

Setelah dilakukan perhitungan kebutuhan air pada tahun 2018, berikut perhitungan proyeksi kebutuhan air untuk tahun 2028 yaitu seperti pada Tabel 10 dan Tabel 11.

Tabel 10. Perkiraan Jumlah pelanggan tahun 2028 di PDAM Samboja:

\begin{tabular}{lc}
\hline Jenis pelayanan & Jumlah pelanggan \\
\hline KELOMPOK (1) & \\
Sosial Khusus 1 (I.2) & 27 \\
Sosial Khusus 2 (I.3) & 41 \\
\hline KELOMPOK (II) & \\
Rumah Tangga B (II.1) & 3280 \\
Instansi Pemerintah (II.2) & 24 \\
Niaga Kecil (II.3) & 233 \\
Industri Kecil (II.4) & \\
\hline KELOMPOK (III) & \\
Rumah Tangga C (III.1) & 25 \\
Rumah Tangga D (III.2) & 1 \\
Niaga Besar (III.3) & 12 \\
\hline KELOMPOK (IV) & \\
Niaga Besar (IV.1) & 2 \\
\hline TOTAL & 3659 \\
\hline
\end{tabular}

Sumber: Hasil analisis

Tabel 11. Jumlah kebutuhan air bersih tahun 2028

\begin{tabular}{lc}
\hline \multicolumn{1}{c}{ Jenis pelayanan } & $\begin{array}{c}\text { Kebutuhan air bersih } \\
\text { liter/detik }\end{array}$ \\
\hline KELOMPOK (I) & \\
Sosial Khusus 1 (I.2) & 0,888 \\
Sosial Khusus 2 (1.3) & 0,954 \\
\hline KELOMPOK (II) & \\
Rumah Tangga B (II.I) & 24,675 \\
Instansi Pemerintah (II.2) & 5,592 \\
Niaga Kecil (II.3) & 2,697 \\
\hline KELOMPOK (III) & \\
Rumah Tangga C (III.I) & 0,192 \\
Rumah Tangga D (III.2) & 0,010 \\
Niaga Besar I (III.3) & 0,222 \\
\hline KELOMPOK (IV) & \\
Niaga Besar II ( IV.1) & 0,049 \\
\hline TOTAL & 35,282 \\
\hline
\end{tabular}

Sumber: Hasil analisis 
Analisis Kebutuhan Air Bersih..., Irna Hendriyani ${ }^{(1)}$, Martheana Kencanawati ${ }^{(2)}$, Agus Nur Salam ${ }^{(3)}$

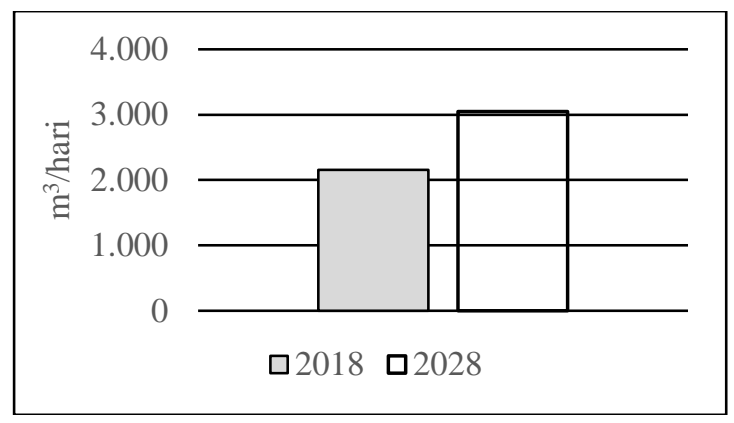

Gambar 2. Perkiraan Kebutuhan Air Bersih

Seperti terlihat pada Gambar 2, maka kebutuhan air pada tahun 2028 adalah 35,282 liter/detik atau $3.048 \mathrm{~m}^{3} /$ hari sedangkan air yang siap didistribusikan setiap harinya sekitar 2.599,5 $\mathrm{m}^{3} /$ hari. Jadi kebutuhan air di daerah pelayanan IPA Samboja di tahun 2028 kekurangan 448,5 $\mathrm{m}^{3} /$ hari atau hanya $83 \%$ pelanggan PDAM yang dapat terlayani.

\section{Ketersediaan Air Bersih}

Kapasitas sumber air bersih yang dikelola oleh PDAM Tirta Mahakam Kecamatan Samboja saat ini sepenuhnya berasal dari Sungai Merdeka. Instalasi Pengolahan Air Tirta Mahakam mengolah air baku di setiap harinya sekitar $2.682 \mathrm{~m}^{3}$ setelah diolah menghasilkan air bersih yang siap didistribusikan sekitar 2.599,5 $\mathrm{m}^{3}$. Perkiraan kebutuhan air untuk tahun 2028 adalah 3.048 $\mathrm{m}^{3} /$ hari seperti terlihat pada Tabel 11 .

Tabel 11. Ketersediaan dan Kebutuhan Air

\begin{tabular}{llc}
\hline $\begin{array}{c}\text { Sumber Mata } \\
\text { Air }\end{array}$ & $\begin{array}{c}\text { Air yang } \\
\text { tersedia }\end{array}$ & $\begin{array}{c}\text { Air yang } \\
\text { dibutuhkan }\end{array}$ \\
\hline $\begin{array}{l}\text { Sungai } \\
\text { Merdeka }\end{array}$ & $\begin{array}{l}2.599,5 \\
\mathrm{~m}^{3} / \mathrm{hari}\end{array}$ & $3.048 \mathrm{~m}^{3} / \mathrm{hari}$ \\
\hline
\end{tabular}

Berdasarkan data diatas:

Kapasitas produksi air bersih, $\left(\mathrm{Q}_{\text {total }}\right)$ adalah 2.599,5 $\mathrm{m}^{3} /$ hari. Sementara kapasitas air bersih sampai tahun $2028\left(\mathrm{Q}_{\text {total }}\right)$ adalah $3.048 \mathrm{~m}^{3} /$ hari. Maka terjadi kekurangan produksi air bersih sebanyak $448,5 \mathrm{~m}^{3} /$ hari

Jadi IPA Tirta Mahakam Kecamatan Samboja jika hanya memiliki 2 pompa untuk 10 tahun kedepannya tidak dapat melayani daerah pelayanan. Untuk itu diperlukan penambahan 1 pompa agar IPA Tirta Mahakam Samboja tetap dapat melayani kebtuhan pelanggan pada 10 tahun mendatang

\section{PENUTUP}

\section{Kesimpulan}

Kapasitas air bersih IPA PDAM Tirta Mahakam Samboja dengan 2 pompa, sebesar 2.599,5 $\mathrm{m}^{3} /$ hari pada tahun 2018. Dengan perkiraan hasil jumlah pelanggan pada 10 tahun yang akan datang diperoleh jumlah kebutuhan air sebesar $3.048 \mathrm{~m}^{3} /$ hari, maka diperlukan penambahan 1 pompa agar tetap dapat melayani kebutuhan pelanggannya.

\section{DAFTAR PUSTAKA}

Agustini, Maya. (2016), Analisa Kebutuhan Air Bersih IPA PDAM Batu Ampar, Skripsi, Prodi Teknik Sipil Universitas Balikpapan,

Chay, (1995), Standar-standar Kualitas Air

Departemen Kesehatan RI, No 416 tahun 1990 tentang Peraturan Menteri Kesehatan

Keputusan Menteri Kesehatan, No. 1405 tahun 2002 tentang Persyaratan Kesehatan Lingkungan Kerja Perkantoran dan Industri

Kusnoputranto, Haryoto, (2000), Kesehatan Lingkungan. Fakultas Kesehatan Masyarakat Universitas Indonesia,

Nurdijanto, (2000), Kimia Lingkungan

Peraturan Daerah Nomor 13 Tahun 2002, tentang Susunan Organisasi dan Tata Kerja Perusahaan Daerah Air Minum

Peraturan Daerah Kabupaten Kutai Kartanegara, Nomor 13 tahun 2002 tentang Susunan Organisasi dan Tata Kerja Perusahaan Daerah Air Minum

Peraturan Menteri Kesehatan, No. 416 tahun 1990 tentang Syarat-Syarat Dan Pengawasan Kualitas Air

Peraturan Menteri Kesehatan, No. 416 tahun 1990 tentang Persyaratan Kualitas Air Bersih

Peraturan Pemerintah, No. 82 Tahun 2001 tentang Pengelolaan dan Pencemaran Air

Peraturan Pemerintah Republik Indonesia, No. 8 tahun 2002 tentang perubahan nama Kabupaten Kutai Menjadi Kabupaten Kutai Kartanegara

www.Wikipedia.org, Siklus Hidrologi. 